\title{
Simulasi Numerik Karakteristik Aliran Melintasi Silinder Sirkular dengan Plat Splitter Dekat Dinding Miring
}

\author{
Varien Janitra Nuralif Susanto dan Wawan Aries Widodo \\ Departemen Teknik Mesin, Fakultas Teknologi Industri \\ Institut Teknologi Sepuluh Nopember (ITS) 60111 Indonesia \\ e-mail: wawanaries@me.its.ac.id
}

\begin{abstract}
Abstrak-Analisis struktural adalah salah satu pekerjaan yang dilakukan dalam proses rekayasa teknik. Interaksi fluida dengan struktur merupakan salah satu pokok analisis dalam analisis struktural. Salah satu contoh kasus interaksi fluida dengan struktur adalah aliran melintasi silinder sirkular. Pipa merupakan elemen silinder sirkular yang sering ditemui di industri. Industri perminyakan offshore umumnya meletakkan pipa dekat dengan dasar laut yang menghasilkan karakteristik aliran tertentu. Karakteristik yang dipengaruhi oleh peletakan tersebut adalah distribusi tekanan. Distribusi tekanan yang berbeda turut menghasilkan gaya yang berbeda, sehingga membutuhkan perlakuan khusus saat instalasi. Karakteristik lainnya adalah vortex shedding. Studi terdahulu menyatakan bahwa pemasangan plat splitter dengan panjang tertentu akan meredam vortex shedding dan mengurangi gaya drag. Penelitian ini dilakukan dengan metode simulasi numerik dua dimensi dengan pemodelan turbulensi SST $\mathbf{k}-\omega$. Aliran diasumsikan steady dan incompressible dan mengalir pada bilangan Reynolds $5 \times 10^{4}$. Domain simulasi yang digunakan berupa silinder sirkular dengan plat splitter yang diletakkan dinding dengan kemiringan tertentu pada besar celah tertentu. Variasi pada penelitian ini adalah kemiringan dinding $\alpha\left[0^{\circ}, 10^{\circ}, 20^{\circ}\right]$ dan rasio besar celah dengan diameter silinder sirkular G/D $[0,1$; $0,2 ; 0,3 ; 0,4 ; 0,5]$. Hasil yang didapatkan dari simulasi numerik ini adalah bahwa peningkatan G/D dan $\alpha$ pada umumnya akan menurunkan $C_{D p}$ dan $C_{L p}$. Pada variasi besar celah dan $\alpha=0^{\circ}$ didapati $C_{D p}$ maksimum pada G/D 0,2, sedangkan $C_{L p}$ menurun secara konsisten. Pada $\alpha=10^{\circ}$ didapati $C_{D p}$ maksimum dan $C_{L p}$ minimum pada G/D 0,2. Pada $\alpha=20^{\circ}$ didapati $C_{D p}$ meningkat secara konsisten pada G/D $>0,2$ dan $C_{L p}$ minimum pada G/D 0,4. Pada variasi kemiringan dinding dan $G / D<0,3$ didapati $C_{L p}$ memiliki nilai minimum pada $\alpha=10^{\circ}$, namun $C_{D p}$ menurun secara konsisten. Karakteristik aliran diatas sangat dipengaruhi oleh fenomena blockage dan adverse pressure gradient.
\end{abstract}

Kata Kunci-Dinding, Drag, Koefisien Tekanan, Lift, Silinder Sirkular, Splitter.

\section{PENDAHULUAN}

$\mathrm{P}$ EMBANGUNAN negara Indonesia memiliki hubungan yang erat dengan rekayasa teknik. Salah satu rekayasa teknik yang dilakukan dalam melakukan pembangunan adalah analisis struktural. Interaksi antara fluida dengan struktur merupakan salah satu pokok analisis yang dilakukan pada suatu struktur. Salah satu kasus interaksi fluida dengan struktur adalah aliran yang melintasi silinder sirkular. Contoh aplikasi interaksi fluida dengan struktur berbentuk silinder sirkular pada industri adalah instalasi pipa yang terbenam didalam laut. Instalasi pipa yang terbenam didalam laut adalah hal yang umum ditemukan pada industri perminyakan lepas pantai.
Posisi instalasi pipa yang terbenam didalam laut pada umumnya diletakkan dekat dengan dasar laut. Posisi peletakan pipa yang dekat dengan dasar laut ini memiliki pengaruh yang signifikan terhadap karakteristik aliran yang melintasi pipa. Karakteristik aliran tersebut telah dipelajari oleh [1] dengan melakukan eksperimen pada silinder sirkular yang diletakkan dekat dinding dengan menggunakan wind tunnel. Eksperimen ini dilakukan pada bilangan Reynolds $2,5 \times 10^{4}$ dan $4,8 \times 10^{4}$ yang didasarkan pada diameter silinder. Variasi eksperimen dilakukan pada rasio G/D yang merupakan rasio antara besar celah dengan diameter silinder sirkular. Hasil yang didapatkan dari eksperimen ini melalui analisis spektral menunjukkan bahwa fenomena vortex shedding pada silinder sirkular terjadi dengan bilangan Strouhal yang konstan untuk $\mathrm{G} / \mathrm{D} \geq 0,3$. Vortex shedding yang terjadi akan teredam apabila silinder sirkular didekatkan dengan dinding $(\mathrm{G} / \mathrm{D}<0,3)$. Hasil eksperimen lain yang didapatkan melalui pengamatan distribusi tekanan menunjukkan bahwa terdapat pembentukan wake pada sisi upstream dan downstream dinding. Wake tersebut akan melekat pada silinder sirkular saat rasio $\mathrm{G} / \mathrm{D}=0$. Peningkatan G/D akan menghasilkan distribusi tekanan yang lebih simetris. Distribusi tekanan hampir simetris sempurna saat G/D mencapai nilai 0,4. Pada G/D yang rendah titik separasi di sisi bawah silinder sirkular bergeser menuju trailing edge akibat adanya gradien tekanan yang favourable.

Penelitian oleh [1] menunjukkan bahwa terdapat fenomena vortex shedding pada silinder sirkular yang diletakkan dekat dinding. Vortex shedding memberikan beban dinamis pada silinder sirkular, sehingga peluang kegagalan struktur menjadi semakin besar. Masalah tersebut dapat dihindari dengan memasang plat pada sisi upstream dan downstream silinder sirkular. Penelitian [2] mempelajari peredaman vortex shedding pada silinder sirkular melalui eksperimen pada silinder sirkular dengan pemasangan plat frontal, wake atau splitter, dan bilateral. Eksperimen tersebut dilakukan dalam wind tunnel pada bilangan Reynolds yang divariasikan pada rentang $6,90 \times 10^{4}$ hingga $8,28 \times 10^{5}$. Hasil yang didapatkan dari eksperimen oleh [2] adalah penambahan plat frontal dengan rasio $\mathrm{L} / \mathrm{D}=3$ (rasio panjang plat terhadap diameter silinder sirkular) menghasilkan aliran post-critical pada bilangan Reynolds yang relatif rendah. Aliran postcritical tersebut timbul akibat adanya gangguan pada aliran upstream. Hasil yang didapatkan dari silinder sirkular dengan pemasangan plat bilateral pada kondisi yang serupa adalah vortex shedding pada silinder sirkular teredam oleh plat splitter dengan $\mathrm{L} / \mathrm{D}=3$. Shear layer yang terseparasi pada silinder sirkular dengan plat bilateral mengalami transisi pada

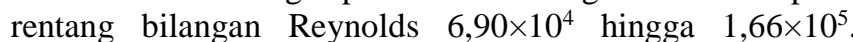
Transisi shear layer tersebut mengakibatkan fluktuasi pada 
distribusi tekanan. Rata-rata dan fluktuasi distribusi tekanan menjadi relatif lebih stabil ketika bilangan Reynolds lebih besar dari $1,66 \times 10^{5}$.

Penelitian pengaruh pemasangan plat splitter pada silinder sirkular yang lain dilakukan oleh [3]. Penelitian [3] melakukan eksperimen pada silinder sirkular dengan pemasangan plat splitter pada sisi downstream. Plat splitter yang digunakan pada eksperimen ini dapat berputar secara bebas terhadap sumbu silinder dan divariasikan pada L/D 0,5 hingga 6,0. Eksperimen dilakukan pada rentang bilangan Reynolds $3 \times 10^{4}$ hingga $6 \times 10^{4}$. Hasil yang didapatkan dari eksperimen menunjukkan bahwa plat splitter yang bebas bergerak memiliki deviasi sudut $\delta$ terhadap sumbu horizontal. Deviasi tersebut disebabkan oleh perbedaan tekanan pada kedua sisi plat splitter. Posisi deviasi plat splitter tidak menunjukkan kecenderungan untuk berada pada sisi atas maupun sisi bawah silinder. Rasio L/D memiliki pengaruh yang signifikan pada sudut deviasi plat splitter. Plat splitter yang lebih panjang akan menghasilkan sudut deviasi yang lebih kecil. Pada L/D $\geq 4$ sudut $\delta$ menjadi 0 , sehingga plat splitter paralel terhadap sumbu horizontal. Dapat disimpulkan bahwa vortex shedding teredam dengan menggunakan plat splitter dengan $\mathrm{L} / \mathrm{D} \geq 4$. Penambahan plat splitter juga menghasilkan reduksi koefisien drag rata-rata hingga $30 \%$ dan reduksi root-mean-square koefisien lift fluktuatif sebesar 90\%. Hasil eksperimen menunjukkan bahwa plat splitter yang bebas bergerak memperpanjang daerah pembentukan vortex dan mencegah interaksi antara shear layer pada kedua sisi silinder.

Pada penelitian yang sama, [4] melakukan simulasi numerik aliran pada silinder sirkular dengan plat splitter dekat dinding yang bergerak. Pemodelan aliran turbulen yang digunakan pada simulasi ini adalah model large-eddy based lattice boltzmann. Variasi yang dilakukan pada simulasi ini adalah G/D antara 0,1 hingga 3,0. Simulasi dilakukan pada bilangan Reynolds pada rentang 200 hingga 400. Hasil yang didapatkan dari simulasi adalah vortex shedding pada sisi bawah silinder sirkular teredam saat $G / D \leq 0,2$. Rasio G/D yang menurun mengakibatkan peningkatan frekuensi vortex shedding hingga suatu nilai maksimum, kemudian menurun secara kontinyu. Koefisien drag dan lift yang didapatkan lebih rendah dibandingkan dengan silinder sirkular tanpa plat splitter. Hasil simulasi numerik oleh [4] telah sesuai dengan eksperimen dan simulasi sebelumnya.

Berdasarkan hasil penelitian-penelitian tersebut, maka permasalahan dari penelitian ini adalah analisis karakteristik aliran yang melintasi silinder sirkular dengan plat splitter dekat dinding miring menggunakan simulasi numerik. Variasi yang dilakukan adalah kemiringan dinding dari sudut $0^{\circ}, 10^{\circ}$, dan $20^{\circ}$ dengan rasio G/D dari 0,1 hingga 0,5 . Selain karakteristik aliran, permasalahan dari penelitian ini adalah bagaimana distribusi dari koefisien tekanan $\left(C_{p}\right)$ pada silinder sirkular dengan plat splitter dan pada dinding miring. Selain distribusi koefisien-koefisien gaya, nilai koefisien drag tekanan $\left(\mathrm{C}_{\mathrm{Dp}}\right)$ dan koefisien lift tekanan $\left(\mathrm{C}_{\mathrm{Lp}}\right)$ dari silinder sirkular dengan plat splitter turut menjadi permasalahan pada penelitian ini.

\section{URAIAN PENELITIAN}

Analisis karakteristik aliran pada silinder sirkular dengan plat splitter dilakukan dengan melakukan pemodelan domain simulasi seperti pada gambar 1 dibawah berikut. Domain simulasi terdiri dari silinder sirkular dengan diameter sebesar
D yang dipasangkan plat splitter dengan panjang $L$ dan tebal $\mathrm{T}$ pada sisi wake. Silinder sirkular tersebut diletakkan dekat dengan dinding yang memiliki kemiringan $\alpha$ terhadap bidang horizontal. Variasi yang dilakukan pada geometri adalah besar celah $(G)$ dan kemiringan dinding $(\alpha)$. Nilai-nilai variabel geometri yang telah dituliskan diatas adalah $\mathrm{D}=40$ $\mathrm{mm}, \mathrm{L}=\mathrm{D}$, dan $\mathrm{T}=0,05 \mathrm{D}$.

Domain pada gambar 1 akan dilakukan proses meshing seperti gambar 2. Jenis meshing yang digunakan pada penelitian ini adalah two-dimensional quadrilaterateral structured mesh. Pemilihan jenis mesh tersebut ditujukan untuk mendapatkan akurasi hasil simulasi dan konvergensi simulasi yang baik. Mesh tersebut akan diproses oleh ANSYS Fluent 19.0 Student Version untuk melakukan proses simulasi numerik. Pembuatan mesh diulangi untuk tiap variasi.

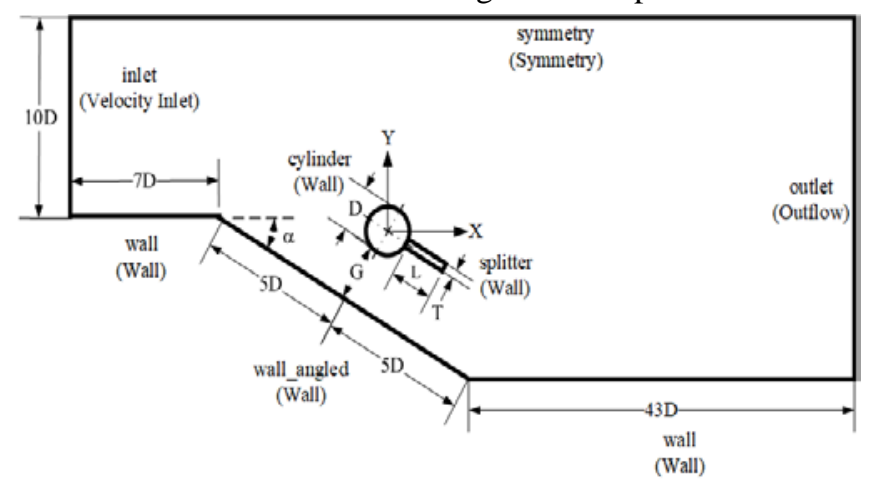

Gambar 1. Domain simulasi dari karakteristik aliran melintasi silinder sirkular dengan plat splitter dekat dinding miring

Pemodelan fenomena fisis yang dipilih pada penelitian ini adalah pressure-based solver, steady flow, dan Shear Stress Transport k- $\omega$ turbulence modeling. Pemilihan pemodelan turbulen Shear Stress Transport k- $\omega$ dipilih berdasarkan literatur [5] yang menyatakan bahwa pemodelan turbulensi Shear Stress Transport k- $\omega$ memberikan performa yang terbaik untuk kasus simulasi pada umumnya dan kasus aliran eksternal seperti adverse pressure gradient dan free shear layer. Pemodelan turbulensi Shear Stress Transport k- $\omega$ juga memiliki performa baik dalam menganalisis aliran yang dekat dengan dinding.

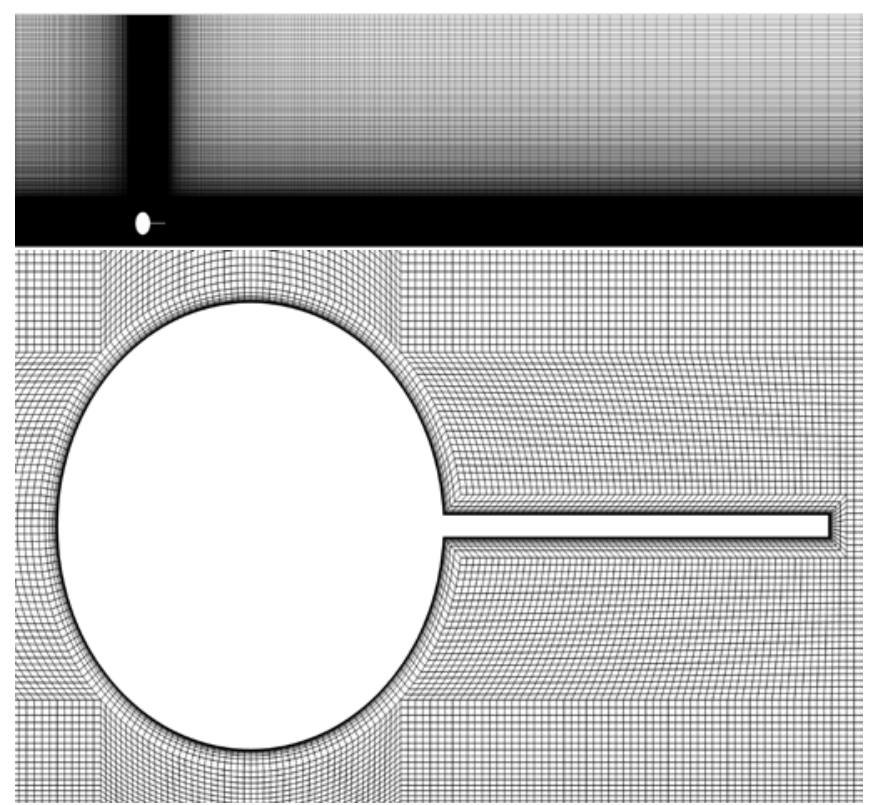

Gambar 2. Meshing dari domain (atas) dan silinder sirkular dan plat splitter (bawah)

Fluida kerja yang digunakan pada penelitian ini adalah udara dengan temperatur $300 \mathrm{~K}$ pada tekanan atmosfer. 
Properti udara didapatkan dari literatur [6]. Nilai-nilai yang dimasukkan pada boundary condition didasarkan pada literatur yang telah ada. Bilangan Reynolds yang digunakan pada penelitian ini adalah $5 \times 10^{4}$ berdasarkan literatur [3] dan [7]. Data-data yang diperlukan untuk melakukan pemodelan turbulensi pada sisi inlet adalah intensitas turbulensi diketahui dari [3] sebesar $0,1 \%$ dan length scale sebesar $0,00443 \mathrm{~m}$. Nilai length scale didapatkan dari persamaan (1) berikut:

$$
l=0,4 \delta_{99}=0,4\left(\frac{0,382 R e^{4 / 5} \mu}{\rho V}\right)
$$

Dengan mengasumsikan bahwa aliran pada inlet telah melintasi plat datar dan berada pada kondisi tepat transisi menuju turbulen. Persamaan diatas didapatkan dari[8].

Grid independency test dilakukan mulai dari mesh yang renggang (coarse), menengah (medium), rapat (fine), dan sangat rapat (very fine). Nilai yang dibandingkan pada grid independency test adalah koefisien drag tekanan dari silinder. Pengamatan pada dan tabel 1 menunjukkan bahwa nilai $C_{D p}$ tidak berubah signifikan pada tingkat kerapatan mesh 295 ribu dan 360 ribu nodes. Kesimpulan tersebut didukung oleh kesalahan relatif yang cukup rendah yaitu 0,054\%. Berdasarkan pengamatan tersebut, maka tingkat kerapatan mesh yang digunakan pada penelitian ini adalah kerapatan mesh dengan jumlah nodes 295 ribu.

Tabel 1.

Perbandingan nilai $\mathrm{C}_{\mathrm{Dp}}$ pada proses Grid Independency Test

\begin{tabular}{cccc}
\hline \hline Jumlah Nodes & $\mathbf{Y}^{+}$ & $\mathbf{C}_{\mathbf{D p}}$ & Kesalahan Relatif (\%) \\
\hline 185 ribu & 0,495 & 0,8675 & - \\
235 ribu & 0,330 & 0,8690 & 0,169 \\
295 ribu & 0,330 & 0,8698 & 0,094 \\
360 ribu & 0,165 & 0,8693 & 0,054 \\
\hline \hline
\end{tabular}

\section{A. Persamaan-persamaan yang Digunakan}

Persamaan-persamaan yang digunakan pada penelitian ini adalah Bilangan Reynolds, Koefisien Tekanan, Koefisien Drag dan Lift Tekanan, dan Integrasi Komposit Simpson's Rule.

Bilangan Reynolds terdiri dari densitas $\rho$, kecepatan freestream $\mathrm{V}_{\infty}$, diameter silinder sirkular $\mathrm{D}$, dan viskositas absolut $\mu$.

$$
R e=\frac{\rho V_{\infty} D}{\mu}
$$

Koefisien tekanan merupakan rasio antara gaya tekanan yang terjadi pada suatu bodi dengan gaya inersia fluida. Koefisien tekanan terdiri dari tekanan kontur p, tekanan freestream $\mathrm{p}_{\infty}$, densitas $\rho$, dan kecepatan freestream $\mathrm{V}_{\infty}$

$$
C_{\boldsymbol{p}}=\frac{p-p_{\infty}}{\frac{1}{2} \rho V_{\infty}^{2}}
$$

Koefisien drag tekanan merupakan integrasi dari koefisien tekanan. Koefisien ini menunjukkan gaya drag pada bodi yang dihasilkan dari tekanan. Koefisien ini terdiri dari $C_{p}$ kontur dan sudut posisi kontur $\theta$. Gaya drag memiliki arah sejajar dengan sumbu x pada Gambar 3.

$$
C_{D p}=\frac{1}{2} \int_{0}^{2 \pi} C_{p} \cos \theta d \theta
$$

Koefisien lift tekanan merupakan integrasi dari koefisien tekanan. Koefisien ini menunjukkan gaya lift pada bodi yang dihasilkan dari tekanan. Koefisien ini terdiri dari $\mathrm{C}_{\mathrm{p}}$ kontur dan sudut posisi kontur $\theta$. Gaya lift memiliki arah sejajar dengan sumbu y pada Gambar 3.

$$
C_{L p}=-\frac{1}{2} \int_{0}^{2 \pi} C_{p} \sin \theta d \theta
$$

Evaluasi nilai integral dari koefisien drag dan lift didapatkan dengan menggunakan integrasi komposit Simpson's Rule. Rumus Simpson's Rule terdiri dari batas atas data $\mathrm{b}$, batas atas data a, jumlah data $\mathrm{n}$, data ke $\mathrm{i} \mathrm{x}_{\mathrm{i}}$, index $\mathrm{i}$ dan j:

$$
\begin{aligned}
\int_{a}^{b} f(x) d x \approx \frac{b-a}{3 n} & {\left[f\left(x_{0}\right)+4 \sum_{i=1}^{i=1,3,5, \ldots} f\left(x_{i}\right)\right.} \\
& \left.+2 \sum_{j=2}^{j=2,4,6, \ldots} f\left(x_{j}\right)+f\left(x_{n}\right)\right]
\end{aligned}
$$

Persamaan (2) hingga (5) diatas mengacu pada gambar 3 berikut:

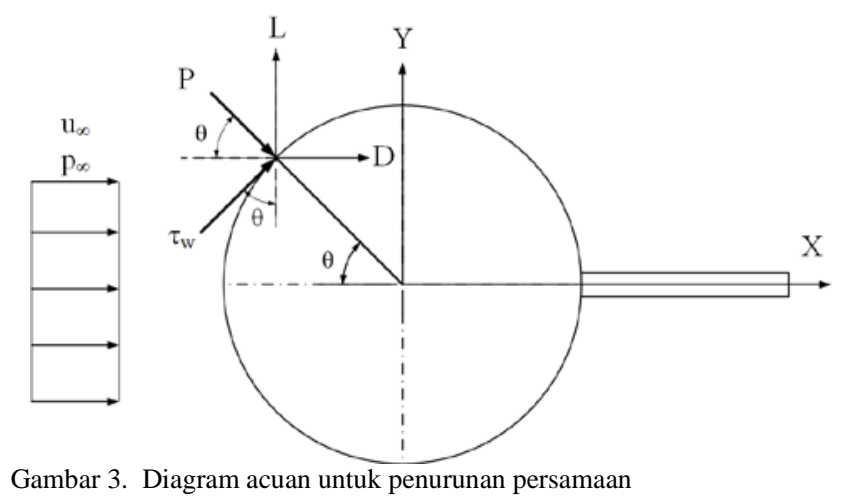

\section{HASIL SIMULASI NUMERIK}

\section{A. Pengaruh G/D Terhadap Karakteristik Aliran pada Variasi $\alpha=0^{\circ}$}

Pengamatan secara sekilas pada gambar 4 menunjukkan bahwa pada G/D 0,1 $\mathrm{C}_{\mathrm{p}}$ memiliki distribusi yang tampak berbeda apabila dibandingkan dengan G/D yang lain. Pengamatan yang lebih detail menunjukkan bahwa distribusi Cp sisi atas (sudut $0^{\circ}-180^{\circ}$ ) silinder sirkular dengan G/D 0,1 memiliki $C_{p}$ minimum yang lebih rendah dari $G / D$ lainnya. Hal ini menunjukkan bahwa pada G/D 0,1 aliran mengalami percepatan yang lebih tinggi dibandingkan pada G/D lainnya. Gambar 4 juga menunjukkan bahwa pada G/D 0,1 aliran pada sisi atas juga mengalami perlambatan yang lebih tinggi dibandingkan G/D lainnya. Perlambatan yang lebih tinggi tersebut menghasilkan rata-rata tekanan sisi atas-belakang (sudut $90^{\circ}-180^{\circ}$ ) yang lebih tinggi dibandingkan G/D lainnya. Untuk $\mathrm{G} / \mathrm{D} \geq 0,2$, distribusi $\mathrm{C}_{\mathrm{p}}$ sisi atas tidak memiliki perbedaan yang signifikan.

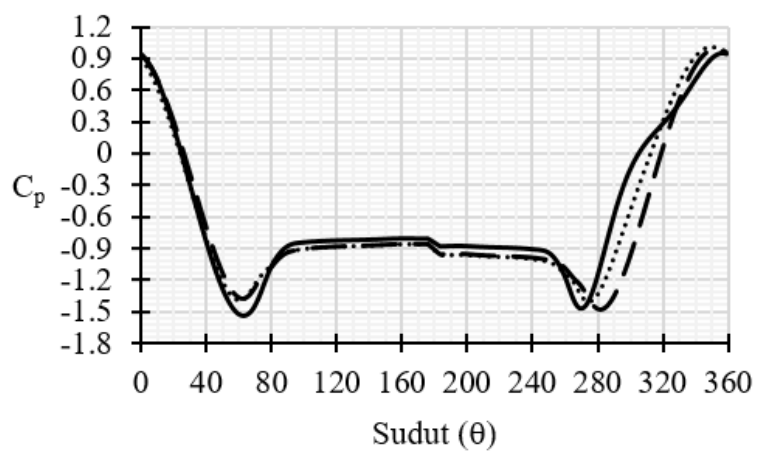

$-\mathrm{G} / \mathrm{D}=0.1 \cdots \cdots \cdot \mathrm{G} / \mathrm{D}=0.2-\mathrm{G} / \mathrm{D}=0.5$

Gambar 4. Distribusi $C_{p}$ Silinder Sirkular tiap G/D pada Variasi $\alpha=0^{\circ}$ 
Pengamatan pada distribusi $\mathrm{C}_{\mathrm{p}}$ sisi bawah (sudut $180^{\circ}$ $360^{\circ}$ ) silinder sirkular menunjukkan bahwa pada G/D 0,1 $\mathrm{C}_{\mathrm{p}}$ maksimum memiliki nilai yang lebih rendah dibandingkan dengan G/D lainnya. $C_{p}$ maksimum akan meningkat dan bergeser menuju trailing edge saat $\mathrm{G} / \mathrm{D}$ ditingkatkan menuju 0,2. Posisi $\mathrm{C}_{\mathrm{p}}$ maksimum akan bergeser menuju trailing edge, namun nilainya tidak berubah secara signifikan saat $G / D$ ditingkatkan lebih lanjut. Pengamatan pada $C_{p}$ minimum menunjukkan bahwa $C_{p}$ minimum akan meningkat saat $G / D$ ditingkatkan menuju 0,2 dan kembali menurun saat G/D ditingkatkan lebih lanjut. Posisi $\mathrm{Cp}$ minimum bergeser menuju leading edge secara konsisten apabila G/D ditingkatkan.

Pengamatan lain menunjukkan bahwa pada G/D 0,1 aliran mengalami percepatan yang lebih rendah secara signifikan pada sisi bawah-depan (sudut $270^{\circ}-360^{\circ}$ ) dibandingkan dengan G/D lainnya. Percepatan tersebut akan semakin tinggi saat G/D ditingkatkan. Hal ini ditunjukkan dengan mengamati $\mathrm{Cp}$ pada satu titik sudut, dimana $\mathrm{C}_{\mathrm{p}}$ menurun secara konsisten saat G/D ditingkatkan. Selain itu, aliran juga mengalami perlambatan yang lebih tinggi pada G/D 0,1 dibandingkan dengan rasio G/D lainnya. Perlambatan ini menghasilkan rata-rata tekanan sisi bawah-belakang (sudut $180^{\circ}-270^{\circ}$ ) yang lebih tinggi dari rasio G/D lainnya. Perlambatan tersebut tidak mengalami perubahan yang signifikan pada $\mathrm{G} / \mathrm{D} \geq 0,2$.

\section{B. Pengaruh G/D Terhadap Karakteristik Aliran pada Variasi $\alpha=10^{\circ}$}

Pengamatan secara sekilas pada Gambar 5 menunjukkan bahwa tiap G/D memiliki distribusi $C_{p}$ yang berbeda antara satu dengan yang lain. Pengamatan yang lebih detail pada distribusi $C_{p}$ sisi atas silinder sirkular menunjukkan bahwa $C_{p}$ maksimum pada G/D 0,1 lebih rendah dari G/D lainnya. $C_{p}$ maksimum yang rendah ini disebabkan oleh titik stagnasi yang berada pada daerah boundary layer sehingga terjadi viscous dissipation yang menghilangkan energi dari aliran. $\mathrm{C}_{\mathrm{p}}$

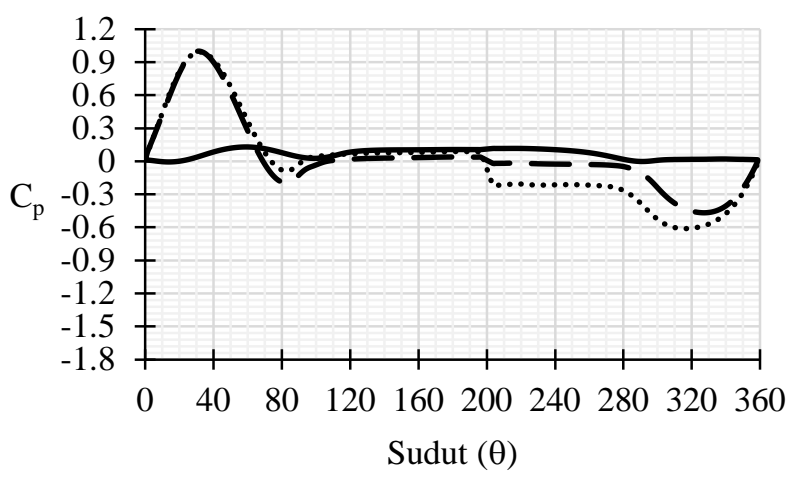

$\longrightarrow \mathrm{G} / \mathrm{D}=0.1 \cdots \cdots \cdot \mathrm{G} / \mathrm{D}=0.4-\mathrm{G} / \mathrm{D}=0.5$

Gambar. 6. Distribusi $C_{p}$ Silinder Sirkular tiap G/D pada Variasi $\alpha=20^{\circ}$

maksimum tersebut meningkat dan bergeser menuju leading edge saat G/D ditingkatkan menuju 0,2. Peningkatan G/D lebih lanjut hanya menggeser $\mathrm{C}_{\mathrm{p}}$ maksimum menuju leading edge. Pengamatan pada $C_{p}$ minimum menunjukkan bahwa $C_{p}$ minimum pada G/D 0,1 lebih rendah dari G/D lainnya. Apabila G/D ditingkatkan menjadi 0,2, maka $C_{p}$ minimum akan meningkat. Walaupun $\mathrm{C}_{\mathrm{p}}$ minimum pada $\mathrm{G} / \mathrm{D}$ 0,2 lebih tinggi, namun perlambatan aliran pada G/D 0,1 lebih besar dibandingkan G/D 0,2. Hal ini menghasilkan rata-rata tekanan sisi atas-belakang yang lebih besar. $\mathrm{C}_{\mathrm{p}}$ minimum dan rata-rata tekanan sisi atas-belakang menurun apabila G/D ditingkatkan.

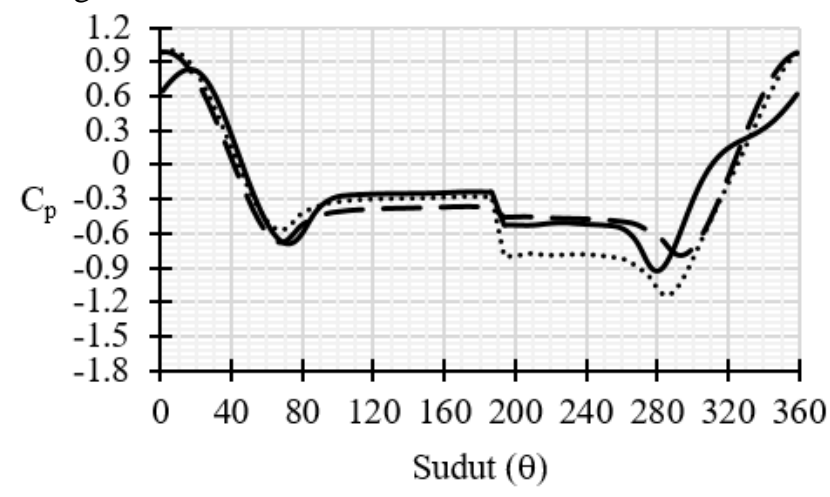

$-\mathrm{G} / \mathrm{D}=0.1 \cdots \cdots \cdot \mathrm{G} / \mathrm{D}=0.2--\mathrm{G} / \mathrm{D}=0.5$

Gambar 5. Distribusi $C_{p}$ Silinder Sirkular tiap G/D pada Variasi $\alpha=10^{\circ}$

Pengamatan pada distribusi $C_{p}$ sisi bawah silinder sirkuar menunjukkan bahwa $C_{p}$ maksimum pada G/D 0,1 memiliki nilai yang lebih rendah dibandingkan $G / D$ lainnya. $C_{p}$ maksimum meningkat dan posisinya bergeser menuju leading edge saat G/D ditingkatkan. Peningkatan G/D lebih lanjut hanya menggeser posisi $\mathrm{C}_{\mathrm{p}}$ maksimum menuju leading edge. Pengamatan lain pada $\mathrm{C}_{\mathrm{p}}$ minimum menunjukkan bahwa $C_{p}$ minimum pada $G / D$ 0,1 memiliki nilai yang relatif lebih rendah dibandingkan G/D lainnya. Apabila G/D ditingkatkan menuju 0,2, maka $C_{p}$ minimum menurun secara signifikan menjadi lebih rendah dari G/D lainnya. Hal ini menghasilkan rata-rata tekanan sisi bawah-belakang yang lebih rendah dari G/D lainnya walaupun perlambatan pada G/D 0,1 lebih tinggi. Peningkatan G/D lebih lanjut akan meningkatkan $\mathrm{C}_{\mathrm{p}}$ minimum dan rata-rata tekanan bawahbelakang.

\section{Pengaruh G/D Terhadap Karakteristik Aliran pada Variasi $\alpha=20^{\circ}$}

Pengamatan secara sekilas pada Gambar 6 menunjukkan bahwa G/D 0,1 memiliki distribusi $\mathrm{C}_{\mathrm{p}}$ yang berbeda dengan $\mathrm{G} / \mathrm{D}$ lainnya. Gambar 6 juga menunjukkan bahwa rata-rata $C_{p}$ pada $\mathrm{G} / \mathrm{D} \leq 0,3$ mendekati 0 , sehingga pembahasan distribusi $\mathrm{C}_{\mathrm{p}}$ secara detail hanya dilakukan hanya pada $\mathrm{G} / \mathrm{D}$ 0,4 dan 0,5.

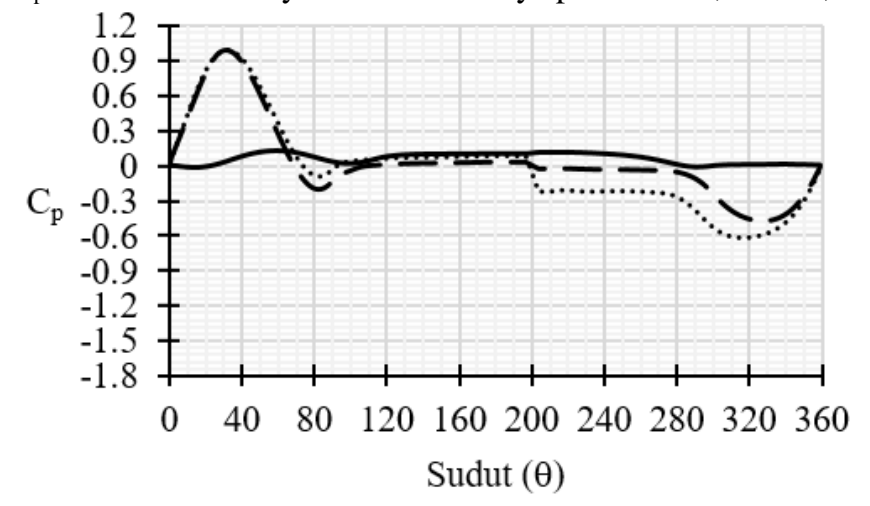

$$
-\mathrm{G} / \mathrm{D}=0.1 \cdots \cdots \cdot \mathrm{G} / \mathrm{D}=0.4--\mathrm{G} / \mathrm{D}=0.5
$$

Gambar 6. Distribusi $C_{p}$ Silinder Sirkular tiap G/D pada Variasi $\alpha=20^{\circ}$

Pengamatan secara detail pada distribusi $C_{p}$ sisi atas silinder sirkular menunjukkan bahwa $C_{p}$ maksimum pada G/D 0,4 dan 0,5 memiliki nilai dan posisi yang kurang lebih sama. Namun pengamatan pada $C_{p}$ minimum menunjukkan bahwa $C_{p}$ minimum pada G/D 0,4 lebih tinggi dibandingkan 
G/D 0,5. Hal ini menunjukkan bahwa pada G/D 0,5 terjadi percepatan aliran yang lebih tinggi dibandingkan G/D 0,4. Percepatan aliran yang lebih tinggi tersebut menghasilkan rata-rata tekanan sisi atas-belakang yang lebih rendah. Pengamatan lain pada distribusi Cp sisi bawah menunjukkan bahwa $\mathrm{C}_{\mathrm{p}}$ minimum pada G/D 0,4 lebih rendah dari G/D 0,5. Peningkatan G/D menghasilkan peningkatan $\mathrm{C}_{\mathrm{p}}$ minimum dan menggeser posisinya menuju leading edge.

\section{Koefisien Drag dan Lift Tekanan}

Koefisien drag dan lift didapatkan dari hasil integrasi dari koefisien tekanan silinder sirkular pada gambar 4 hingga 6 diatas. Sehingga didapatkan grafik pada Gambar 7 dan 8 . Didapatkan bahwa nilai $C_{D p}$ menurun secara konsisten apabila $\alpha$ ditingkatkan. Berbeda dari $\mathrm{C}_{\mathrm{Dp}}, \mathrm{C}_{\mathrm{Lp}}$ memiliki nilai minimum pada $\alpha=10^{\circ}$ untuk $\mathrm{G} / \mathrm{D} \leq 0,3$ dan menurun apabila $\mathrm{G} / \mathrm{D}>0,3$. Hal ini dikarenakan pada $\mathrm{G} / \mathrm{D} \leq 0,3$ silinder sirkular berada pada daerah resirkulasi, sehingga nilai $\mathrm{C}_{\mathrm{Lp}}$ pada $\alpha=10^{\circ}$ lebih rendah akibat selisih tekanan yang lebih besar.
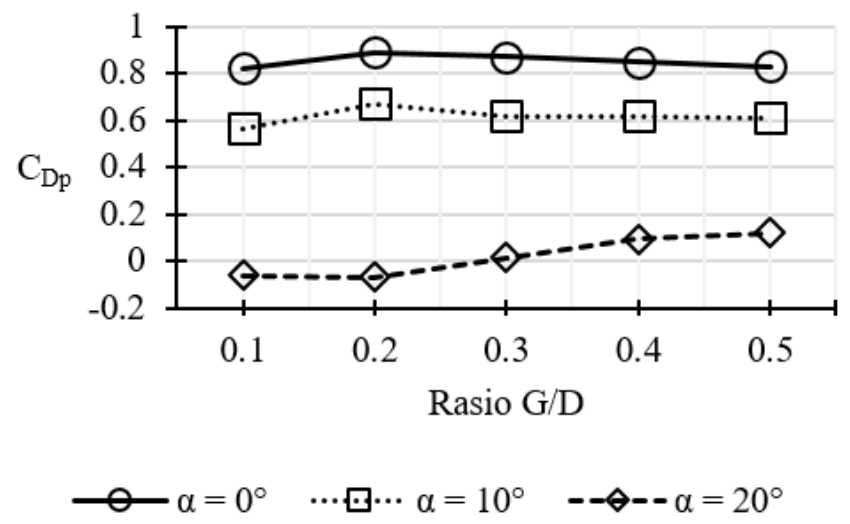

Gambar 7. Nilai $C_{D p}$ tiap $G / D$ pada berbagai variasi $\alpha$

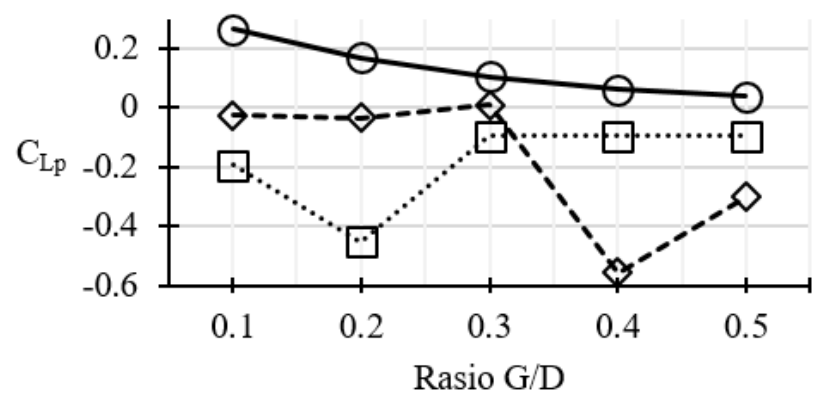

$\neg \alpha=0^{\circ} \quad \cdots \boxminus \cdots \alpha=10^{\circ} \quad--\diamond--\alpha=20^{\circ}$

Gambar 8. Nilai $\mathrm{C}_{\mathrm{Lp}}$ tiap G/D pada berbagai variasi $\alpha$

Perilaku $C_{\text {Dp }}$ dan $C_{\text {Lp }}$ pada $\alpha=0^{\circ}$ disebabkan oleh adanya fenomena blockage pada aliran. Blockage adalah fenomena aliran yang terhambat akibat adanya peningkatan tekanan yang dihasilkan dari pelebaran streamtube. Blockage ditunjukkan oleh adanya wake pada upstream silinder sirkular pada Gambar 9. Blockage memengaruhi $\mathrm{C}_{\mathrm{Dp}}$ dengan menurunkan tekanan pada sisi bawah-depan silinder sirkular.
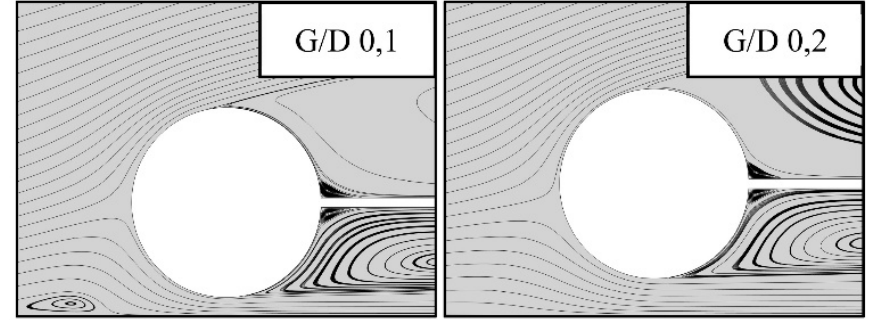

Gambar. 9. Streamline pada $\alpha=0^{\circ}$

Selain blockage, nilai $\mathrm{C}_{\mathrm{p}}$ maksimum silinder sirkular yang kurang dari 1 pada G/D 0,1 menunjukkan silinder sirkular yang sudah berada didalam boundary layer dari dinding. $\mathrm{C}_{\mathrm{p}}$ maksimum yang kurang dari 1 tersebut disebabkan oleh adanya viscous dissipation pada aliran, sehingga energi aliran berkurang dan menurunkan tekanan stagnasi. Hal tersebut berdampak ke $\mathrm{C}_{\mathrm{Dp}}$ silinder sirkular. Saat G/D ditingkatkan menuju 0,2 maka pengaruh blockage akan menurun, sehingga tekanan pada sisi bawah-depan meningkat dan meningkatkan $\mathrm{C}_{\mathrm{Dp}}$. Peningkatan $\mathrm{G} / \mathrm{D}$ lebih lanjut akan menurunkan $\mathrm{C}_{\mathrm{Dp}}$ akibat distribusi tekanan sisi atas dan bawah yang menjadi lebih simetris. Simetri dari distribusi tekanan tersebut akan menurunkan $\mathrm{C}_{\mathrm{Lp}}$.

Perilaku $C_{D p}$ dan $C_{L p}$ pada $\alpha=10^{\circ}$ memiliki kesamaan dengan $\alpha=0^{\circ}$. Peningkatan $\mathrm{C}_{\mathrm{Dp}}$ pada G/D 0,2 disebabkan oleh pengaruh blockage yang berkurang. Nilai $\mathrm{C}_{\mathrm{Dp}}$ yang lebih rendah dari $\alpha=0^{\circ}$ disebabkan oleh momentum aliran upstream yang hilang akibat adverse pressure gradient dari dinding, sehingga tekanan stagnasi turut berkurang. Peningkatan G/D menuju 0,3 akan menghasilkan $C_{D p}$ yang konstan. Hal tersebut menunjukkan pengaruh dinding yang berkurang. Sedangkan penurunan $C_{\mathrm{Lp}}$ pada G/D 0,2 disebabkan oleh percepatan aliran sisi bawah yang tinggi pada G/D 0,2 seperti yang ditunjukkan oleh gambar 10, sehingga tekanan sisi bawah jauh lebih rendah dari sisi atas. Percepatan aliran sisi bawah tersebut menurun saat G/D ditingkatkan menuju 0,3 sehingga $\mathrm{C}_{\mathrm{Lp}}$ akan menurun.

Perilaku $C_{D p}$ dan $C_{\text {Lp }}$ pada $\alpha=20^{\circ}$ pada $G / D \geq 0,4$ sama dengan $\alpha=10^{\circ}$ pada $G / D \geq 0,2$ seperti yang terlihat di gambar 7 dan 8. Hal tersebut disebabkan oleh adanya akselerasi aliran yang tinggi pada $\mathrm{G} / \mathrm{D}$ tertentu. Untuk $\alpha=10^{\circ}$ akselerasi aliran tertinggi terjadi pada G/D 0,2 dan untuk $\alpha=20^{\circ}$ pada G/D 0,4 pada gambar 11 . Untuk $\mathrm{G} / \mathrm{D}<0,4$ perilaku aliran disebabkan oleh silinder sirkular yang berada pada daerah resirkulasi dinding. Nilai $C_{D p}$ dan $C_{L p}$ yang masih berubah pada G/D > 0,4 menunjukkan bahwa dinding masih memiliki pengaruh terhadap aliran.

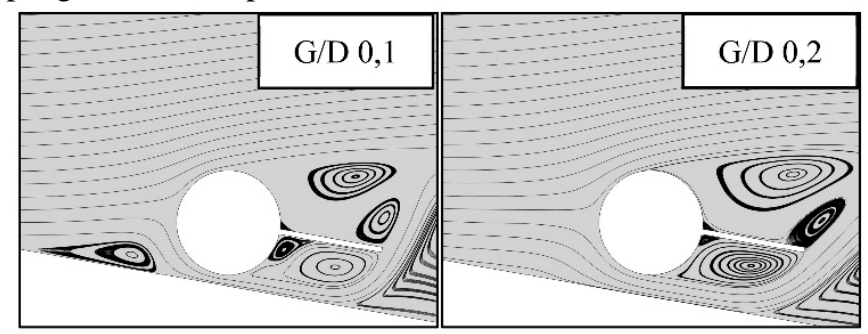

Gambar. 10. Streamline pada $\alpha=10^{\circ}$ 


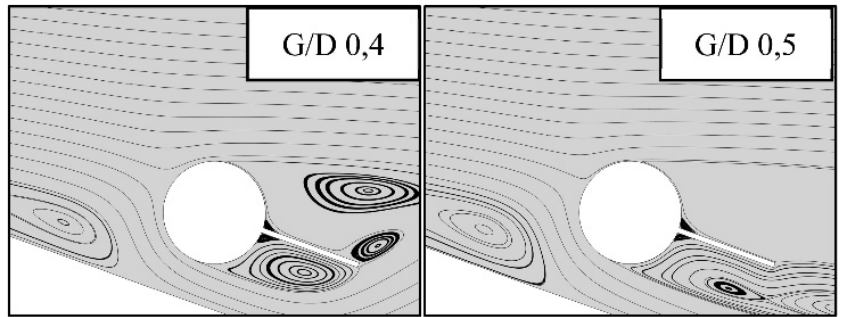

Gambar. 11. Streamline pada $\alpha=20^{\circ}$

\section{KESIMPULAN}

1) Pada $\alpha=0^{\circ}, C_{D p}$ maksimum terletak pada G/D 0,2, peningkatan $\mathrm{G} / \mathrm{D}$ akan menghasilkan penurunan $\mathrm{C}_{\mathrm{Dp}}$ secara konsisten. Sedangkan $\mathrm{C}_{\mathrm{Lp}}$ menurun secara konsisten apabila G/D ditingkatkan.

2) Pada $\alpha=10^{\circ}, C_{D p}$ maksimum terletak pada G/D 0,2. Peningkatan G/D menuju 0,3 akan menurunkan $\mathrm{C}_{\mathrm{Dp}}$. Peningkatan G/D > 0,3 akan menghasilkan $\mathrm{C}_{\mathrm{Dp}}$ yang konstan. Sedangkan $C_{L p}$ memiliki nilai negatif pada seluruh $\mathrm{G} / \mathrm{D}$ dan nilai $\mathrm{C}_{\mathrm{Lp}}$ minimum terdapat pada $\mathrm{G} / \mathrm{D}$ 0,2 . Peningkatan G/D menuju 0,3 akan meningkatkan $\mathrm{C}_{\mathrm{Lp}}$. Peningkatan $\mathrm{G} / \mathrm{D}>0,3$ menghasilkan $\mathrm{C}_{\mathrm{Lp}}$ yang konstan.

3) Pada $\alpha=20^{\circ}, \mathrm{C}_{\mathrm{Dp}}$ konstan dan memiliki nilai negatif pada $\mathrm{G} / \mathrm{D} \leq 0,2$. Pembesaran $\mathrm{G} / \mathrm{D} \geq 0,3$ menghasilkan $\mathrm{C}_{\mathrm{Dp}}$ yang meningkat secara konsisten dan bernilai positif. Sedangkan $\mathrm{C}_{\mathrm{Lp}}$ memiliki nilai yang konstan pada $\mathrm{G} / \mathrm{D}<$ 0,3. Peningkatan G/D menuju 0,4 akan menurunkan $\mathrm{C}_{\mathrm{Lp}}$ menuju minimum. Peningkatan G/D menuju 0,5 meningkatkan $\mathrm{C}_{\mathrm{Lp}}$.

4) Peningkatan $\alpha$ akan menurunkan $C_{D p}$ secara konsisten, sedangkan $\mathrm{C}_{\mathrm{Lp}}$ memiliki nilai minimum pada $\alpha=10^{\circ}$ untuk G/D $\leq 0,3$. Apabila G/D ditingkatkan menuju G/D $>0,3$ maka $C_{L p}$ menurun secara konsisten saat $\alpha$ ditingkatkan.

5) Blockage membelokkan sebagian besar massa aliran menuju sisi atas dan menciptakan perbedaan tekanan antara sisi atas dengan sisi bawah-depan.

6) Adverse pressure gradient menurunkan momentum aliran upstream sehingga menghasilkan tekanan stagnasi maksimum yang lebih rendah dan meningkatkan ratarata tekanan pada sisi bawah-belakang silinder sirkular.

\section{DAFTAR PUSTAKA}

[1] P. W. Bearman and M. M. Zdravkovich, "Flow around a circular cylinder near a plane boundary,” J. Fluid Mech., vol. 89, no. 1, pp. 33-47, Nov. 1978.

[2] Y. Qiu, Y. Sun, Y. Wu, and Y. Tamura, "Effects of splitter plates and Reynolds number on the aerodynamic loads acting on a circular cylinder,” J. Wind Eng. Ind. Aerodyn., vol. 127, pp. 40-50, Apr. 2014.

[3] F. Gu, J. S. Wang, X. Q. Qiao, and Z. Huang, "Pressure distribution, fluctuating forces and vortex shedding behavior of circular cylinder with rotatable splitter plates,” J. Fluids Struct., vol. 28, pp. 263-278, Jan. 2012.

[4] H. Zhang and W. Shi, "Numerical simulation of flow over a circular cylinder with a splitter plate near a moving wall,” Ocean Eng., vol. 122, pp. 162-171, Aug. 2016.

[5] H. K. Versteeg and W. Malalasekera, An introduction to computational fluid dynamics: the finite volume method. Harlow, Essex : Pearson Education Ltd, 2007.

[6] T. L. Bergman and F. P. Incropera, Fundamentals of heat and mass transfer., 7 ed. New Jersey: Wiley, 2011.

[7] W. A. Widodo, "Pemodelan numerik aliran melintasi dua silinder sirkulasi tersusun tandem dengan pengaruh side wall dengan jarak gap (G/D =0.2), ” in Prosiding Seminar Nasional Perkembangan Riset dan Teknologi di Bidang Industri ke 16, 2010.

[8] R. W. Fox, P. J. Pritchard, and A. T. McDonald, Fox and McDonald's introduction to fluid mechanics., 8th ed./. Hoboken NJ: John Wiley \& Sons, Inc., 2011. 